
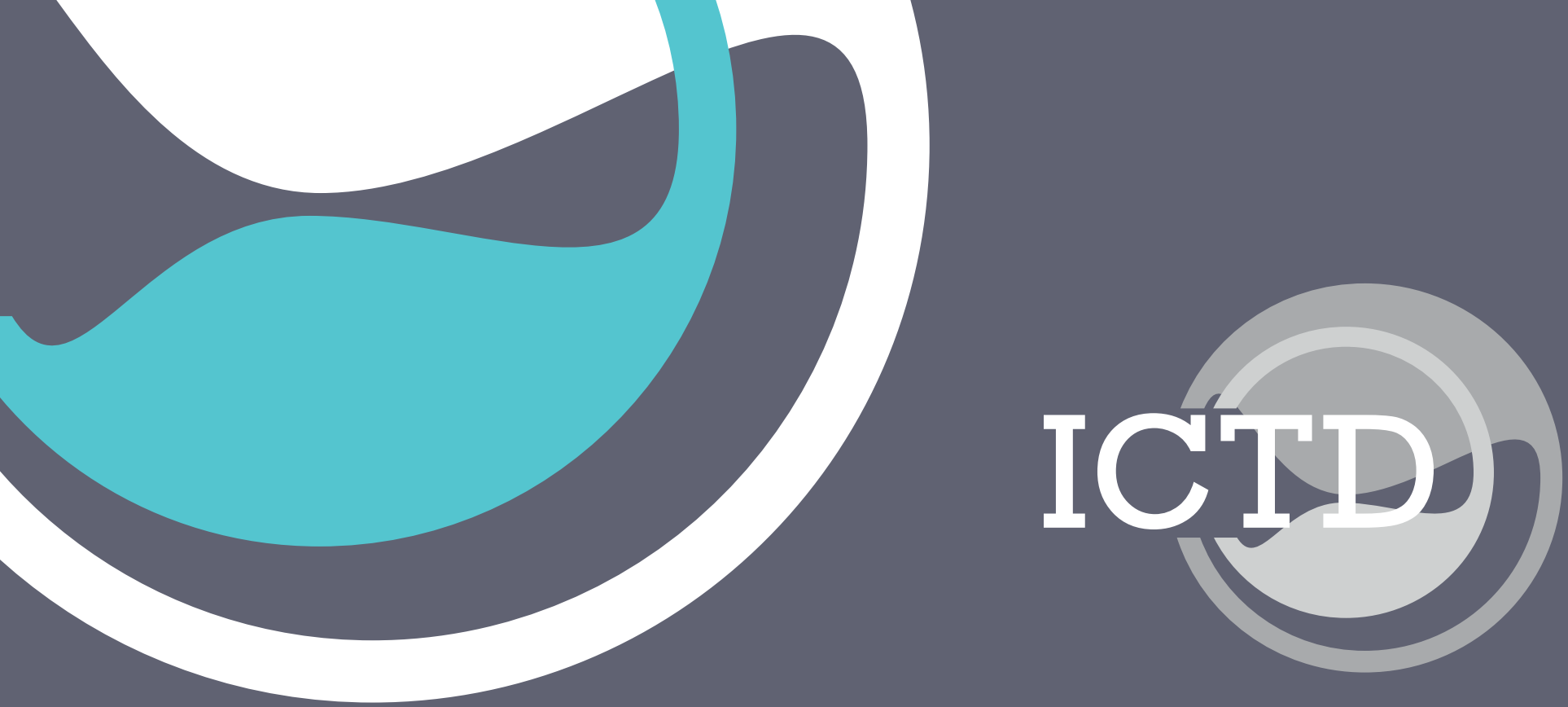

Working Paper 137

\title{
Digital financial services and digital IDs: What potential do they have for better taxation in Africa?
}

Fabrizio Santoro, Laura Munoz, Wilson Prichard and Giulia Mascagni

Feloruary 2022

BILL \& MELINDA

GATES foundation
(2) institute of development studies
MR UKaid 
ICTD Working Paper 137

Digital financial services and digital IDs: What potential do they have for better taxation in Africa?

Fabrizio Santoro, Laura Munoz, Wilson Prichard and Giulia Mascagni

February 2022 
Digital financial services and digital IDs: What potential do they have for better taxation in Africa? Fabrizio Santoro, Laura Munoz, Wilson Prichard and Giulia Mascagni ICTD Working Paper 137

First published by the Institute of Development Studies in February 2022

(C) Institute of Development Studies 2022

ISBN: 978-1-78118-915-3

DOI: $10.19088 /$ ICTD.2022.003

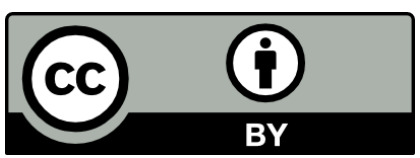

This is an Open Access paper distributed under the terms of the Creative Commons Attribution 4.0 International license (CC BY), which permits unrestricted use, distribution, and reproduction in any medium, provided the original authors and source are credited and any modifications or adaptations are indicated.

http://creativecommons.org/licenses/by/4.0/legalcode

Available from:

The International Centre for Tax and Development at the Institute of Development Studies, Brighton BN1 9RE, UK

Tel: +44 (0) 1273606261 Fax: +44 (0) 1273621202

E-mail: info@ictd.ac.uk

Web: ictd.ac/publication

Twitter: twitter.com/ICTDTax

Facebook: facebook.com/ICTDTax

LinkedIn: linkedin.com/company/ICTDTax

IDS is a charitable company limited by guarantee and registered in England

Charity Registration Number 306371

Charitable Company Number 877338 


\title{
Digital financial services and digital IDs: What potential do they have for better taxation in Africa?
}

\author{
Fabrizio Santoro, Laura Munoz, Wilson Prichard and Giulia Mascagni
}

\section{Summary}

New digital technologies are now being widely used in Africa and lower-income countries (LICs). This has had an impact on tax administration, which has been increasingly digitised. Specifically Digital Financial Services (DFS) and digital IDs can improve tax administration. They have the potential to identify taxpayers more easily, communicate with them better, enforce and monitor compliance, and reduce compliance costs.

While the potential is clear, existing literature indicates some of the barriers. Take-up of digital technology is still low due to barriers. Also, when taking up the technology, taxpayers often tend to adopt various measures to minimise tax payments. Within tax administrations there are challenges to accessibility and use of quality data. Mistakes can be made when launching digitisation, and there are regulatory and political barriers for effective use of digital technology.

Given this context, this paper summarises key questions that are relevant for research and policy development to make more effective use of digital technology in tax administration in Africa and LICs.

Keywords: Digital technology; tax administration; barriers for effective use.

Fabrizio Santoro is a Research Fellow at the Institute of Development Studies and at the International Centre for Tax and Development, as well as Research Lead of the DIGITAX Programme.

Laura Munoz is the Programme Lead of the DIGITAX Programme.

Wilson Prichard is the CEO of the ICTD, an Associate Professor at the University of Toronto, and a Research Fellow at the Institute of Development Studies. He is the author of Taxation, Responsiveness, and Accountability in Sub-Saharan Africa: The Dynamics of Tax Bargaining.

Giulia Mascagni is a Research Fellow at the Institute of Development Studies and Research Director of the International Centre for Tax and Development. 


\section{Contents}

Summary 3

Acknowledgements

Acronyms $\quad 5$

$1 \quad$ Introduction $\quad 6$

$2 \quad$ The potential of DFS and digital IDs in the context of LICs 7

3 Can the promises of digital ID and DFS data be realised? Insights from existing evidence on data and IT in tax administration 8

$4 \quad$ An agenda for policy and research $\quad 12$

$\begin{array}{ll}\text { References } & 13\end{array}$ 


\section{Acknowledgements}

The authors would like to thank Mick Moore, Moyosore Awera and Giovanni Occhiali for their support with this paper.

\section{Acronyms}

\author{
DFS \\ Digital IDs \\ E-filing \\ E-payment \\ EFDs \\ ITAS \\ LIC
}

Digital financial services

Digital identities

Electronic/online filing of taxes

Electronic/online payment of taxes

Electronic fiscal devices

Integrated technology and applied systems

Lower-income country 


\section{Introduction}

New digital technologies are now being widely used in lower-income countries (LICs). This raises the question whether these can be used to develop more effective, equitable and accountable tax systems. The expansion of digital financial services (DFS) - all those digital means of performing financial transactions (payments, transfers, deposits, etc.), such as mobile money - and the gradual expansion of foundational digital ID systems, ${ }^{1}$ have attracted particular interest.

In recent times, tax administrations in Africa, and LICs in general, have become increasingly digitised (World Bank 2016; IMF 2020). Revenue authorities in Africa have started automating their internal processes through the launch of integrated technology and applied systems (ITAS). ${ }^{2}$ They also inaugurated e-services for taxpayers, such as filing taxes online, and using electronic fiscal devices (Kochanova et al. 2016; IMF 2020). Revenue authorities use these, although not fully, to perform their core functions of identification, facilitation, enforcement and analysis (Okunogbe and Santoro 2021). Current challenges with data usage and IT adoption are likely to influence the capacity of revenue authorities to use new data from DFS and digital IDs.

At least in theory, DFS and digital IDs could help African revenue authorities to improve performance of a number of core functions, including:

i. identifying and communicating with taxpayers more easily, thanks to higher-quality data on taxpayer profiles;

ii. reducing compliance costs, and assisting taxpayers to comply by means of digital payments; and

iii. enforcing and monitoring compliance, again through access to better information.

In addition, significant benefits could come from higher-quality data produced by DFS and digital IDs, ranging from increased transparency and reduced corruption in the tax system. This could result in more objective data-driven audits, to better governance and management practices in revenue authorities - such as more rigorous statistical analysis, and forecasting based on better information.

While the potential is clear, what are the barriers to achieving these outcomes? These questions remain largely unanswered in the existing literature. This paper seeks to highlight three central questions for which existing knowledge remains limited:

1) What is the nature and potential of these new technologies in the context of LICs specifically, given their unique economic structures, capacity and patterns of usage?

2) Given the relative lack of evidence relating to DFS, digital IDs and taxation, what can we learn from the use of existing data and technology in LIC tax administrations? What does this experience tell us about the potential of using other sources of data (such as DFS) to improve tax administration?

There are many variants of 'digital ID', see https://www.thalesgroup.com/en/markets/digital-identity-andsecurity/government/identity/digital-identity-services/trends. Our focus is on government-sanctioned ID schemes at the national level (foundational) or agency level (functional), and how these two dimensions augment tax administration. In practice, these national ID schemes are by far the most important. Only $18 \%$ of lower- and middle-income countries have a digital ID scheme for identification alone; $55 \%$ have some form of digital ID system for specific services like voting, cash transfers or e-health. Only $3 \%$ have functional and cross-governmental digital ID systems that help citizens access a wide variety of public services (source: World Bank ID4D database).

2 Customs departments pioneered digitisation in tax administration, and domestic tax departments became involved with digitisation later. We are aware that integration between the two systems is not always optimal, but we consider the discussion of interface issues to be outside the scope of this paper. 


\section{The potential of DFS and digital IDs in the context of LICs}

There are many potential benefits to tax administrations and taxpayers from DFS and digital IDs in LICs:

Identifying taxpayers. One of the key challenges of tax administration is to identify the taxpaying population, and to be able to reach them when needed. This challenge is two-fold many taxpayers remain entirely outside the tax net, and the revenue authority often has inaccurate information for those who are registered (Mayega et al. 2019; Moore 2020). The central promise of digital ID technologies for tax administrations is that every taxpayer will be connected to a verified ID. ${ }^{3}$ This is important because it allows:

- The possibility of improving management of taxpayer registries. This could be by ensuring governments can access data (such as taxpayers' name, contact details and location) of higher quality, which is not produced by taxpayer self-reports and/or errorprone manual input; improving their ability to link businesses to underlying individual owners of those businesses; and ensuring effective communication with taxpayers/clients. ${ }^{4}$

- The potential to improve data sharing between institutions. This can be used to identify non-compliance with tax rules (together with a wider range of data from third-party sources, especially on incomes and assets). This would be possible as all citizens would be uniquely identified by one ID, rather than different organisations assigning different IDs that cannot be linked to one another (Mengistu and Mascagni 2018).

Some revenue authorities in Africa, such as Uganda, Malawi and Nigeria, are already using national ID systems to improve tax administration, by integrating this data source (digital ID) with taxpayer registries. In practice, this has allowed them to automatically pull the information on identity of taxpayers (name, gender, address and contact details) that is contained in national ID registries.

Monitoring and enforcement. Moving away from a cash-based economy is key to allowing better taxpayer monitoring and enforcement. DFS can play an important part in this respect unlike cash payments, they allow transactions to be traced through the data trail left by mobile money or other forms of digital payment. ${ }^{5}$ In addition, data from digital payments could also allow data-driven audits and a more transparent tax administration, which relies more on data that is clearly verifiable and less on the action of a specific tax official (Ouedraogo and Sy 2020; Okunogbe and Pouliquen 2022). When there is full integration of administrative tax data and data from DFS at the firm level, the tax administration can also check whether a firm's tax declarations are consistent with payments recorded digitally for

This could also be the case with corporate taxpayers, with company shareholders being connected to national ID databases.

$4 \quad$ Timely and exhaustive communication has become imperative. Multiple channels have become available to revenue authorities, from traditional mailings to cheaper solutions such as SMS and emails, which can be cost-effective tools to nudge taxpayers to comply (Mascagni and Nell 2021; Hoy et al. 2020). There is also increasing demand for better communication and more training (Mascagni et al. 2019; Santoro et al. 2020).

More specifically, this will make it easier (and cheaper) for governments to track sales made by businesses, and thus improve enforcement of VAT and corporate income tax. 
the same business. ${ }^{6}$ In this respect, efforts to expand digital merchant payments are similar in important ways to efforts across governments to introduce electronic tax registers as a strategy for improving monitoring of and compliance with VAT (Casey and Castro 2015). ${ }^{7}$

Management. Higher-quality data from both digital merchant payments and digital ID systems could improve overall governance and management of revenue authorities. As is already happening, although partially, with existing data, new data could potentially help governments move towards a more data-centric mindset, with greater reliance on key metrics and indicators on which to measure and judge performance (World Bank 2016). A better use of data for core functions, as described above, could eventually translate into improved performance targeting - for instance, a more objective assessment of registration figures, or payment data being automatically matched with taxpayer liabilities - and better restructuring of tasks and staff profiles within revenue authorities.

Improve taxpayer experience. Digitised data and DFS have several advantages for taxpayers, many of them related to the automation of taxpaying processes, like e-filing and epayment. If taxpayers can file and pay taxes electronically, some of the cost of compliance (time spent on transport, waiting in queues, etc.) can be reduced. The whole taxpayer experience becomes less burdensome - for example, through online portals with clear information, and online or phone assistance from tax officials. Paying taxes digitally would also reduce taxpayers' vulnerability to corruption and arbitrary behaviour by tax officials. All processes would be automated and easily verifiable by multiple officials - as opposed to a very personalised relationship with a specific tax official that can potentially turn exploitative. ${ }^{8}$

\section{Can the promise of digital ID and DFS data be realised? Insights from existing evidence on data and IT in tax administration}

We do not yet know much about how data from digital IDs and DFS can be used in tax administration. Very few revenue authorities have attempted to use it, and we have no evaluation of the few experiences that exist so far. However, we can identify at least five main insights from recent research:

1) Take-up of existing technological options is low.

2) Taxpayers respond to technological innovation in different ways, to minimise their tax payments.

3) There are challenges in the accessibility and quality of existing data, as well as how data is used.

4) Mistakes can be made in the process of IT launch and implementation.

5) Broader regulatory and political barriers usually play a role.

\footnotetext{
$6 \quad$ A success story comes from Turkey, where a data warehouse system collects information from both private (including commercial banks) and public organisations to curb VAT fraud and misreporting. The impact of extensive data-matching exercises and a conducive cross-agency administrative environment have been remarkable (Dogan 2011).

7 In more sophisticated settings, as is happening in Rwanda and Uganda, electronic tax registers allow digital merchant payments through credit card or mobile money. In other contexts, like Ethiopia, the registers are more rudimentary and not connected with digital payment platforms. In any case, digital merchant payments share the same policy goal as electronic tax registers - tracking sales through a digital trail to improve compliance.

8 Robust evidence has been produced showing that taxpayers in African countries face significant compliance costs when navigating an often-obscure tax system, and consequently deem it arbitrary and unfair (Aiko and Logan 2014; Isbell 2017; Mascagni et al. 2019).
} 
Low take-up. Governments are becoming increasingly interested in seeing greater use of digital merchant payments, and have provided direct incentives to encourage their adoption. ${ }^{9}$ The same applies to e-filing and e-payment, which are increasingly being made mandatory as a response to COVID-related restrictions (Santoro et al. forthcoming (a)).

The potential of data from DFS would be realised more if take-up of digital merchant payments became standard for all everyday transactions. Likewise, the potential of new data from digital IDs to strengthen tax administration would be seen once the digital ID database has universal coverage.

The take-up of digital technology to pay taxes can depend on having a bank or a mobile money account, access to a computer, internet, sufficient knowledge about IT, and trust in digital technology (Santoro et al. forthcoming (b)). Various attitudes and perceptions to tax also help explain the demand for new technology (Ligon et al. 2019). These can range from fear of audit, to better record-keeping.

Taxpayer behavioural responses. Digital data - such as from DFS-based transactions may be made inaccurate by the people involved in producing it. Evidence from Ethiopia (Mascagni et al. 2021) shows that taxpayers responded to a technological innovation - in this case, the adoption of electronic fiscal devices (EFDs) - by adjusting their tax affairs in ways that are not easily monitorable. An example is simultaneously declaring more reported sales and costs. This study indicates that, even when data is readily available, behavioural responses of taxpayers is another reason why IT innovations might not yield the promised benefits in terms of revenue. ${ }^{10}$ In this sense, DFS in themselves, like other e-services such as EFDs, cannot guarantee full tax compliance, but need to be coupled with more traditional enforcement tools, such as audits and checks. ${ }^{11}$ It is likely that behavioural responses, if not factored into the policy decision, could reduce the impact of the introduction of any new technology. ${ }^{12}$

Data accessibility and use in tax administration. DFS and digital IDs might in principle generate a great deal of valuable data, but would tax administrations be able to make use of it? Existing evidence points to challenges in accessibility and usage with more basic datasets.

First, there could be problems in accessing new data from DFS and digital IDs. Often, due to administrative and bureaucratic reasons (and regulatory hurdles, as discussed below), data sharing between revenue authorities and a range of public actors does not happen systematically. It is rather ad hoc (Ligomeka 2019), and sharing agreements are complicated (Mengistu and Mascagni 2018).

Second, and once they have accessed new data from DFS and digital IDs, it is unclear whether tax administrations are adequately equipped to use this information effectively for their core functions. Revenue authorities in Africa have increasingly become more dataoriented (World Bank 2016; Mascagni et al. 2016; Moore 2020). At the same time, new evidence increasingly points to two deeply-rooted challenges with existing tools and data,

\footnotetext{
$9 \quad$ For instance, the Government of Uruguay created incentives for both firms and consumers to adopt electronic payment technology - subsidies for the rental fee of point-of-sales terminals (POS) for firms, and VAT rebates for credit/debit card payments for consumers. Evidence of impact is rather mixed (Brockmeyer and Somarriba 2021). Success stories come from advanced economies as well, such as Korea (Sung et al. 2017). Similar initiatives have been carried out in Africa, such as mobile money transaction fee waivers in Rwanda.

Similar evidence is produced in Carrillo et al. (2017); Brockmeyer and Hernandez (2019); Slemrod et al. (2017).

In the case of DFS for merchant payments, for instance, merchants could game the system by using personal mobile money accounts to perform business transactions, masked as P2P transfers.

Merchants - even when there are tax credits for adoption - could potentially resist using digital payments if they expect that stronger enforcement would lead to much higher tax liabilities than the initial credit.
} 
which are only partially addressed by the recent investment in ITAS and other digital solutions:

1. The quality of administrative data that a tax administration has (such as taxpayer registries and tax returns data) is often limited in scope, inaccurate or simply missing (Ligomeka 2019; Mayega et al. 2019, 2021). Importantly, data from DFS and digital IDs can potentially have similar issues of data quality as these administrative datasets.

2. The systems and resources available to make effective use of more basic datasets which would affect the usability of new data. Challenges exist with whether:

i. $\quad$ adequate systems (such as ITAS) are properly set up and running;

ii. $\quad$ they are used for even basic analysis (Mascagni et al. 2019);

iii. Staff have the required analytical skills to perform more sophisticated data analysis and cross-checks (Mikuriya and Cantens 2020).

In sum, a key message from the literature on data and technology in tax administration is that the central challenge is often not the need for new digital solutions, but to maximise the use of existing resources (Okunogbe and Santoro 2021). The implication for studies of the potential of digital IDs and DFS for tax administration is to focus attention on whether existing tools and data are being utilised effectively, before charting a strategy to prioritise additional tools and data.

Technology implementation in revenue authorities. The IT strategy and process followed by public institutions when embarking on a new technology is likely to be flawed (World Bank 2016). In principle, the implementation of a new technology should be part of a comprehensive strategy that does not consider piecemeal IT solutions in isolation. It should assess the broader IT capacity and upgrade needs.

However, in practice, different challenges exist. New technologies, as integrated and automated systems, tend to be resisted by staff at different levels. They need to adapt to new working habits and abandon well-rooted practices, without adequate incentives and training (Mayega et al. 2019, 2021; Chalendard et al. 2021). At the same time, adopting new solutions will require the tax administration to be in close contact with the taxpaying population, and to launch sensitisation and awareness campaigns. Budget considerations are also relevant in a context of resource-constrained institutions, which usually resort to donor grants and lending to fund IT upgrades, maintenance, training and sensitisation. At the higher national level, political will is essential to ensure a smooth and coherent adoption of a new technology in tax administrations.

Although literature on technology adoption in public institutions in LICs is rising (World Bank 2016), much less is known about the adoption process of new technologies, such as digital IDs and e-filing/e-payment. Ongoing research is attempting to fill this gap (Occhiali and Akol forthcoming).

Regulatory and political barriers. A broader set of challenges affecting smooth data sharing refers to regulation and politics. For the sensitive matter of regulation, accessing digital ID and DFS data comes with risks. Some of the main regulatory issues include cybersecurity, ${ }^{13}$ data privacy and consumer protection. In practice, data sharing agreements between public institutions in LICs are often non-existent, due to the lack of regulations in the legal framework that would support this data exchange. An example of this is the legitimate need for tax administrations to get access to data from traditional and digital FS providers, in

As they become more data-centred, African revenue authorities are more prone to sensitive data leakage and cyber threats. They will need robust investment in system-wide cybersecurity and cyber risk mitigation solutions (Adelmann et al. 2020). 
order to monitor compliance. Providers do not share their clients' data, as their regulations do not allow them to do that. ${ }^{14}$

In this context, it is crucial to understand how integration with a digital ID system or DFS database for tax purposes fits into the existing regulatory system, and which areas are not covered by the tax code. In many cases, regulation needs to be updated (or developed from scratch) to safely allow data exchange. It is important to look into consumer protection and data privacy issues, and put conducive regulatory frameworks in place. These should maintain a balance between protection and security, and the use of digital ID and DFS data for tax purposes.

There are different aspects to consider at the political level. First, the mere existence of a digital ID platform in contexts that are not fully democratic and open has a political connotation, and implications that must be carefully considered. This technology can increase the ability of governments to restrict, control or surveil citizens (Mengistu and Mascagni 2018; Khan and Roy 2019; Zuboff 2019).

Second, there are challenges in the micro-politics within different government institutions, which are often on different IT journeys. A sustained silo mentality often characterises the internal institutional dynamics - usually owing to the desire of different actors within government to protect their proprietary access to data, and limit external oversight of their activities. ${ }^{15}$ Tax administrations can be on one side, and national identification institutions managing digital IDs on another. Integration with a national ID database would require data sharing agreements and inter-institutional cooperation between a range of public actors, and should take place within a coherent national strategy. ${ }^{16}$ This alignment of interests is often difficult to achieve in practice. National leaders, sometimes opposed to external donors and consultants, need to play a key role in promoting a sense of ownership and commitment across the whole of government - indicating clear priorities, setting up realistic timetables, and assigning adequate budgetary resources (IMF 2020).

Third, there are political implications when deciding who to target when relying on digital ID and, more pertinently, DFS data, especially in the policy-relevant aspect of the fight against the so-called informal sector - a hugely broad and diverse category (Gallien and van den Boogaard 2021). Will these new tools be used primarily to capture small, micro firms and subsistence-level traders (Roy and Khan 2021), or larger, more sophisticated entities and high net worth individuals? The largest taxpayers, who usually contribute more in taxes, are more politically connected - especially in Africa (Kangave et al. 2016). Large business transactions can take place in the e-commerce and gig economy - these are growing in relevance in Africa and are hardly taxed, mainy due to political hesitancy (UNCTAD 2018).

It is essential to understand how a new technology, such as digital IDs and DFS data, once introduced in a system, belongs to a broader technology-driven vision of reform within the country as a whole, and how it eventually connects with and improves functions and processes of other public institutions. ${ }^{17}$ The success of digital ID and DFS data reforms in

$14 \quad$ More developed countries have enacted specific legislation whereby processors of debit or credit cards and electronic payment systems are mandated to report to the tax authorities the gross receipts of enterprises accepting these forms of payments. Legislation in LICs is still mostly undefined.

15 This is often true for different revenue bodies working at the national vis-à-vis sub-national level (de Mello and TerMinassian 2020).

16 As national ID databases do not collect all information needed for tax purposes, integration with other national businessrelated databases is needed - such as those kept by national business registration bureaux or chambers of commerce. However, the impact of database integration on tax performance is rather mixed (Lediga et al. 2020).

17 The Rwandan case shows how technological transformation has been enabled by strong political support from the very top government through the Vision 2020 development plan (Schreiber 2018). Another excellent example of a long-term (2006-2021) digitisation journey is offered by the Mauritius Revenue Authority, which is surely an outlier in Africa. The authority inaugurated its plan in 2006 by integrating three different legacy systems and introduced e-filing in 2007. It launched a fully-integrated ITAS in 2010 , which has been routinely upgraded. It introduced mobile payments and filing in 2013-2014, and eventually went ahead with more and more digitalised solutions, including a digitally-enabled COVID 
public finance lies in assuming a whole-of-government approach, understanding the level of political will and broad national strategy for those reforms - including mapping who are likely to be the winners and losers from this type of digital transformation.

\section{An agenda for policy and research}

Building on the previous sections, we summarise here policy considerations that are relevant for tax administrations to realise the potential of new data sources and technologies, and key areas for policy research:

- What is the revenue authority's baseline situation, existing gaps and shortcomings with data accessibility and usage, and the required skillset? Relatedly, what are the current IT and data practices in African tax administration, and how would they affect the success of DFS and digital ID technology? A preliminary diagnostic assessment could help map the current challenges to be addressed.

- What does the broader context look like, in terms of barriers to uptake and behavioural factors, internal resistance to change, regulatory framework and political barriers? For instance, how to best shape taxpayers' willingness to adopt and correctly use DFS and digital ID technology, and how that leads to improved compliance? How does the specific regulatory and political context in which revenue authorities operate influence technology adoption and implementation?

- Which IT solutions are most appropriate for the development level of the revenue authority? Revenue authorities do not all have the same priorities. While they could be implemented in institutions that are well-equipped with IT, DFS and digital ID innovations may not be the best solution in more challenging contexts. In these situations it is better for revenue authorities to focus on strengthening more basic solutions.

- What is the broader, long-term, reform strategy to support IT development? What would be the broader impact of the revenue authorities' adoption of DFS and digital ID technology on the performance, equity and progressivity of the tax system? It could be key to developing a comprehensive plan and reform strategy where other complementary aspects are addressed, including HR skills and incentives, regulatory updates and taxpayer engagement.

So far very little research has been produced on DFS and digital ID technology in African tax administrations. Researchers should start filling this gap in knowledge working alongside policymakers, and help to inform their decisions with scientific knowledge. There is much exciting future research to be carried out in this direction.

assistance scheme in 2020, and a behavioural insight unit aiming to predict risky behaviour by building on machine learning techniques in 2021 (presentation by Soobhash Sonah, Director of Information System Department at the Nigeria Governors' Forum Technology and Tax Event on 19 April 2021). The Freetown experience described in Prichard et al. (2020) provides a success story at the subnational level. At the other extreme, take-up of e-services for taxpayers in Caribbean countries has been dismally low due to faulty strategic direction (Schlotterbeck 2017). 


\section{References}

Adelmann, F., Elliott, J., Ergen, I., Gaidosch, T., Jenkinson, N., Khiaonarong, T., Morozova, A., Schwarz, N. and Wilson, C. (2020) Cyber Risk and Financial Stability: It's a Small World After All, Staff Discussion Note No. 2000/007, Washington DC: International Monetary Fund

Aiko, R. and Logan, C. (2014) Africa's willing taxpayers thwarted by opaque tax systems, corruption, Policy Paper 7, Afrobarometer

Brockmeyer, A. and Hernandez, M. (2019) Taxation, information, and withholding: evidence from Costa Rica, Policy Research working paper WPS 7600, Washington DC: World Bank Group

and Somarriba, M. (2021) Electronic Payment Technology and Tax Capacity: Evidence from Uruguay's Financial Inclusion Reform, Working Paper

Carrillo, P., Pomeranz, D. and Singhal, M. (2017) 'Dodging the Taxman: Firm Misreporting and Limits to Tax Enforcement', American Economic Journal: Applied Economics 9(2): 144-64, doi:10.1257/app.20140495

Casey, P., and Castro, P. (2015) Electronic Fiscal Devices (EFDs): An Empirical Study of Their Impact on Taxpayer Compliance and Administrative Efficiency, Working Paper No. 15/73, Washington DC: International Monetary Fund, doi:10.5089/9781475521023.001

Chalendard, C., Duhaut, A., Fernandes, A., Mattoo, A., Raballand, G. and Rijkers, B. (2021) Does Better Information Curb Customs Fraud?, Policy Research Working Paper 9802, Washington DC: World Bank

de Mello, L. and Ter-Minassian, T. (2020) Digitalisation Challenges and Opportunities for Subnational Governments, OECD Working Papers on Fiscal Federalism no. 31

Dogan, U. (2011) 'Tools for Risk Management: The Case of Turkey', in M. Khwaja, R. Awasthi and J. Loeprick (eds), Risk-Based Tax Audits: Approaches and Country Experiences, Directions in Development Series, Washington DC: World Bank

Gallien, M. and van den Boogaard, V. (2021) Rethinking Formalisation: A Conceptual Critique and Research Agenda, ICTD Working Paper 56, Brighton: Institute of Development Studies

Hoy, C., McKenzie, L. and Sinning, M. (2020) Improving Tax Compliance without Increasing Revenue: Evidence from Population-Wide Randomized Controlled Trials in Papua New Guinea, IZA Discussion Paper Series No. 13407

IMF (2020) 'Digitalization in Sub-Saharan Africa', in Regional Economic Outlook: SubSaharan Africa, April 2020. COVID-19: An Unprecedented Threat to Development, Washington DC: International Monetary Fund

Isbell, T. (2017) Tax compliance: Africans affirm civic duty but lack trust in tax department, Policy Paper 43, Afrobarometer

Kangave, J., Nakato, S., Waiswa, R. and Zzimbe, P. (2016) Boosting Revenue Collection through Taxing High Net Worth Individuals: The Case of Uganda, Working Paper 45, 
Brighton: Institute of Development Studies

Khan, M. and Roy, P. (2019) Digital identities: a political settlements analysis of asymmetric power and information, Working Paper 015, Anti-Corruption Evidence Research Consortium

Kochanova, A., Hasnain, Z. and Larson, B. (2016) Does E-Government Improve Government Capacity? Evidence from Tax Administration and Public Procurement, Policy Research Working Paper 7657, Washington DC: World Bank, doi:10.1596/1813-94507657.20210802_C2_Framing_Paper.docx

Lediga, C. and Riedel, N. and Strohmaier, K. (2020) What You Do (and What You Don't) Get When Expanding the Net - Evidence from Forced Taxpayer Registrations in South Africa, available at SSRN: http://dx.doi.org/10.2139/ssrn.3616808

Ligomeka, W. (2019) Assessing the Performance of African Tax Administrations: A Malawian Puzzle, ICTD African Tax Administration Paper 14, Brighton: Institute of Development Studies

Ligon, E., Malick, B., Sheth, K., and Trachtman, C. (2019) 'What Explains low Adoption of Digital Payment Technologies? Evidence from Small-Scale Merchants in Jaipur, India', PLoS One 14(7)

Mascagni, G., Mengistu, A. and Woldeyes, F. (2021) 'Can ICTs Increase Tax Compliance? Evidence on Taxpayer Responses to Technological Innovation in Ethiopia', Journal of Economic Behavior \& Organization 189: 172-93

- Monkam, N. and Nell, C. (2016) Unlocking the Potential of Administrative Data in Africa: Tax Compliance and Progressivity in Rwanda, ICTD Working Paper No. 56, Brighton: Institute of Development Studies

— Mukama, D. and F. Santoro (2019) Teach to Comply? Evidence from a Taxpayer Education Programme in Rwanda, ICTD Working Paper 91, Brighton: Institute of Development Studies

— and Nell, C. (2021) 'Tax compliance in Rwanda: Evidence from a field message experiment', Economic Development and Cultural Change 69(2): 587-624

and Santoro, F. (2018) What is the role of taxpayer education in Africa? ICTD African Tax Administration Paper 1, Brighton: Institute of Development Studies

Mayega, J., Ssuuna, R., Mubajje, M., Nalukwago, M. and Muwonge, L. (2019) How Clean Is Our Taxpayer Register? Data Management in the Uganda Revenue Authority, ICTD African Tax Administration Paper No. 12, Brighton: Institute of Development Studies

Waiswa, R., Nabuyondo, J. and Nalukwago, M. (2021) How Clean Are Our Taxpayer Returns? Data Management in Uganda Revenue Authority, ICTD African Tax Administration Paper No. 24, Brighton: Institute of Development Studies

Mengistu, A. and Mascagni, G. (2018) Are There Any Reliable Data on Wages in LowIncome Countries? Observations and Lessons from Ethiopia, ICTD African Tax Administration Paper 2, Brighton: Institute of Development Studies

Mikuriya, K., and Cantens, T. (2020) 'If Algorithms Dream of Customs, Do Customs Officials 
Dream of Algorithms? A Manifesto for Data Mobilisation in Customs', World Customs Journal 14(2): 3-22

Moore, M. (2020) What Is Wrong with African Tax Administration?, ICTD Working Paper 111, Brighton: Institute of Development Studies

Occhiali, G. and Akol, D. (forthcoming) How do African tax administrations adopt a new technology?, ICTD DIGITAX Working Paper, Brighton: Institute of Development Studies

Okunogbe, O. and Pouliquen, V. (2022) 'Technology, Taxation, and Corruption: Evidence from the Introduction of Electronic Tax Filing', American Economic Journal: Economic Policy

and Santoro, F. (2021) The Promise and Limitations of Information Technology for Tax Mobilization, Policy Research working paper WPS 9848,COVID-19 (Coronavirus) Washington DC: World Bank Group http://documents.worldbank.org/curated/en/578571636990683326/The-Promise-andLimitations-of-Information-Technology-for-Tax-Mobilization

Ouedraogo, R. and Sy, A. (2020) Can Digitalization Help Deter Corruption in Africa?, Working Paper No. 2019/68, Washington DC: International Monetary Fund

Prichard, W., Kamara, A. and Meriggi, N. (2020) 'Freetown Just Implemented a New Property Tax System that Could Quintuple Revenue', African Arguments, May 21

Roy, P. and Khan, M. (2021) 'Digitizing Taxation and Premature Formalization in Developing Countries', Development and Change 52(4): 855-877

Santoro, F., Amine, R. and Magongo, T. (forthcoming (a)) Mandating digital tax tools as a response to Covid: evidence from Eswatini, ICTD Working Paper, Brighton: Institute of Development Studies

_ Lees, A., Carreras, M. and Mukamana, T. (forthcoming (b)) Digital divides and tax compliance: Adoption and impacts of e-services in Rwanda, ICTD Working Paper, Brighton: Institute of Development Studies

_ Groening, E., Mdluli, W. and Shongwe, M. (2020) To file or not to file? another dimension of non-compliance: The Eswatini Taxpayer Survey, ICTD Working Paper 110, Brighton: Institute of Development Studies

Schlotterbeck, S. (2017) Tax Administration Reforms in the Caribbean: Challenges, Achievements, and Next Steps, International Monetary Fund

Schreiber, L. (2018) A foundation for reconstruction: building the Rwanda Revenue Authority, 2001-2017, Princeton University, Innovations for Successful Societies, Princeton University

Slemrod, J., Collins, B., Hoopes, J., Reck, D. and Sebastiani, M. (2017) 'Does Credit- Card Information Reporting Improve Small-Business Tax Compliance?', Journal of Public Economics 149: 1-19

Sung, M., Awasthi, R. and Lee, H. (2017) Can Tax Incentives for Electronic Payments Reduce the Shadow Economy? Korea's Attempt to Reduce Underreporting in Retail 
Businesses, Policy Research Working Papers: 7936, World Bank

UNCTAD (2018) UNCTAD B2C E-Commerce Index 2018: Focus on Africa, United Nations

World Bank (2016) World Development Report 2016: Digital Dividends, Washington DC:

World Bank, doi:10.1596/978-1-4648-0671-1

— ID4D Identification for Development database, Washington DC: World Bank, http://data.worldbank.org/data-catalog/id4d -dataset

Zuboff, S. (2019) 'Surveillance Capitalism and the Challenge of Collective Action', New Labour Forum 28(1): 10-29, https://doi.org/10.1177/1095796018819461 